\title{
Combining QTL-seq and linkage mapping to uncover the genetic basis of single vs. paired spikelets in the advanced populations of two- ranked maize $\times$ teosinte
}

Zhengjie Chen ${ }^{1,2 \dagger}{ }^{+}$Dengguo Tang ${ }^{1 \dagger}$, Kun Hu${ }^{1 \dagger}$, Lei Zhang ${ }^{1}$, Yong Yin ${ }^{1}$, Jixing $\mathrm{Ni}^{1}$, Peng Li ${ }^{1}$, Le Wang ${ }^{1}$, Tingzhao Rong ${ }^{1}$ and Jian Liu ${ }^{*}$

\begin{abstract}
Background: Teosinte ear bears single spikelet, whereas maize ear bears paired spikelets, doubling the number of grains in each cupulate during maize domestication. In the past 20 years, genetic analysis of single vs. paired spikelets (PEDS) has been stagnant. A better understanding of genetic basis of PEDS could help fine mapping of quantitative trait loci (QTL) and cloning of genes.

Results: In this study, the advanced mapping populations $\left(\mathrm{BC}_{3} \mathrm{~F}_{2}\right.$ and $\left.\mathrm{BC}_{4} \mathrm{~F}_{2}\right)$ of maize $x$ teosinte were developed by phenotypic recurrent selection. Four genomic regions associated with PEDS were detected using QTL-seq, located on 194.64-299.52 Mb, 0-162.80 Mb, 12.82-97.17 Mb, and 125.06-157.01 Mb of chromosomes 1, 3, 6, and 8, respectively. Five QTL for PEDS were identified in the regions of QTL-seq using traditional QTL mapping. Each QTL explained 1.12-38.05\% of the phenotypic variance (PVE); notably, QTL qPEDS3.1 with the average PVE of $35.29 \%$ was identified in all tests. Moreover, 14 epistatic QTL were detected, with the total PVE of 47.57-66.81\% in each test. The QTL qPEDS3.1 overlapped with, or was close to, one locus of 7 epistatic QTL. Near-isogenic lines (NILs) of QTL qPEDS1.1, aPEDS3.1, qPEDS6.1, and qPEDS8.1 were constructed. All individuals of NIL-qPEDS6.1(MT1) and NIL-qPEDS8.1(MT1) showed paired spikelets (PEDS $=0$ ), but the flowering time was 7 days shorter in the NIL-qPEDS8.1(MT1). The ratio of plants with PEDS $>0$ was low (1/18 to 3/18) in the NIL-qPEDS1.1(MT1) and NIL-qPEDS3.1(MT1), maybe due to the epistatic effect.
\end{abstract}

Conclusion: Our results suggested that major QTL, minor QTL, epistasis and photoperiod were associated with the variation of PEDS, which help us better understand the genetic basis of PEDS and provide a genetic resource for fine mapping of QTL.

Keywords: Maize domestication, Single vs. paired spikelets, QTL-seq, Major QTL, Epistasis, Photoperiod

*Correspondence: liujian@sicau.edu.cn

${ }^{\dagger}$ Zhengjie Chen, Dengguo Tang and Kun Hu contributed equally to this work.

${ }^{1}$ Maize Research Institute, Sichuan Agricultural University, No.211 Huiming Road, Wenjiang District, Chengdu 611130, Sichuan, China Full list of author information is available at the end of the article

\section{Background}

Improvement in grain yield was one of the main goals during maize domestication [1]. Among the many factors that affect the grain yield, grain number per ear is a major determinant. The number of kernels per maize ear had been raised to 200 or more from its closest wild relative teosinte that has 6 to 12 kernels per ear. The single spikelets in teosinte ear were completely transformed 
into paired spikelets in maize ears, with the two ranks of teosinte ear changed into multiple ranks of maize ears [2]; hence, the number of kernels per row or length of ear in maize was significantly increased compared to that in teosinte [3]. Notably, the transformation of single spikelet into paired spikelets could double the kernel number, which was one of the key steps in maize domestication. Dissecting the genetic architecture of single vs. paired spikelets could improve our understanding about procedures of maize domestication and the genetic mechanism of yield improvement. However, studying of single vs. paired spikelets has not progressed much in the past 20 years, and the genetic basis of single vs. paired spikelets remains poorly known.

Scanning electron microscopy (SEM) analysis of inflorescence development revealed that the inflorescence meristem (IM) transforms into spikelet pair meristems (SPM). Subsequently, each SPM produces two distinct spikelet meristems (SM), one sessile SM and one pedicellate SM [4]. Both sessile and pedicellate SM develop normally in maize ear, resulting in paired spikelets. In contrast, the pedicellate SM is aborted in teosinte ear, leading to single spikelets [5].

Several studies were performed to explore the inheritance of single vs. paired spikelets. As early as 1920, Collins and Kempton showed for the first time that the distributions of single vs. paired spikelets were continuous, deviating from the Mendelian pattern of 3:1 in the maize-teosinte $F_{2}$ population $[6,7]$. Later, Langham suggested that single vs. paired spikelets trait was controlled by a single gene [8], but Szabó and Burr inferred that two independent genes on chromosomes 4 and 8 were involved [9]. In contrast, Mangelsdorf [10], Rogers [11] and Doebley et al. [7] indicated that multiple genes plus epistasis governed single vs. paired spikelets. The differences in these results might be due to that different parents were used to develop the segregating populations and different analysis methods were used in these studies. Currently, the number of studies of QTL mapping for single vs. paired spikelets (PEDS) is less than 10. Doebley et al. mapped four QTL related to PEDS in the $\mathrm{F}_{2}$ population of maize race chapalote (Sin 2$) \times Z$. mays Ssp. Mexicana (Doebley 643), located on chromosomes 1 to 4, with the proportion of phenotypic variance $\left(R^{2}\right)$ explained ranging from 0.05 to 0.24 [7]. One year later, three additional QTL for PEDS located on chromosomes 5, 6 and 7 were identified in the same dataset by a modified statistical analysis [12]. Doebley et al. constructed another $F_{2}$ population of maize race reventador (Nay 15$) \times Z$. mays ssp. pamiglumis (Iltis Cochrane 81), and detected five QTL for PEDS on chromosomes 1, 2, 3, and 10, with the $\mathrm{R}^{2}$ of each QTL was 0.07-0.16 [13]. Moreover, Doebley et al. identified four QTL associated with PEDS in the testcross (TC1) population, which were located on chromosomes $1,3,9$, and 10 , explaining $3.0-7.4 \%$ of the phenotypic variance [14]. The QTL (QTL-1 L and QTL-3L) located on chromosomes $1 \mathrm{~L}$ and $3 \mathrm{~L}$ were repeatedly identified in different studies, explaining an average of 26.85 and $32.70 \%$ of the phenotypic variance, respectively $[7,12,13]$. In addition, a significant epistatic interaction between QTL-lL (umc107) and QTL-3L (umc92) that increased the expression of PEDS was identified in the $\mathrm{F}_{2}$ population, and the combined effect of these two QTL was $60 \%[12,15]$. Nevertheless, the combined value was $7.3 \%$ when the maize alleles of these two QTL were introduced into teosinte background, which was much less than that in the $F_{2}$ population, suggesting that a number of epistatic interactions may be involved in the PEDS variation [15].

Traditional QTL mapping typically involves genotyping of dozens to hundreds of individuals in segregating populations, which is time and labor intensive and thus expensive $[16,17]$. In order to overcome these disadvantages, the selective genotyping was proposed to enhance the efficiency of QTL mapping through selectively genotyping individuals with extreme phenotypes [18]. Further, the procedures were simplified by bulked sample analysis (BSA), only genotyping four DNA pools, including a paired bulked DNA pools with opposite or extreme phenotypes and a pair of parents [19]. The rapid development of next-generation sequencing (NGS) technologies accelerated the application of BSA in QTL analysis and fine mapping because it overcame the limitations of marker density [20]. Combining with the NGS and BSA, several methods have been developed for identification of QTL/genes for quantitative traits, including SHOREmap [21], X-QTL [22], NGM [23], MutMap [24], QTL-seq [25, 26], and QTG-Seq [27]. In maize, these new methods have been utilized for detecting candidate genomic regions, QTL and genes for both quality and quantitative traits such as plant height [28], maize lethal necrosis [29], resistance to gibberella stalk rot [30], and fertility restoration of maize CMS-C [31].

In this study, a two-ranked maize (SICAU1212) and teosinte ( $Z$. mays ssp. mexicana) were used as parents to develop the advanced mapping populations $\left(\mathrm{BC}_{3} \mathrm{~F}_{2}\right.$ and $\mathrm{BC}_{4} \mathrm{~F}_{2}$ ) using phenotypic recurrent selection. Firstly, QTL-seq was performed to rapidly identify candidate genomic regions associated with PEDS in five pairs of high PEDS bulks and the low PEDS bulk in the $\mathrm{BC}_{3} \mathrm{~F}_{2}$ populations. Subsequently, traditional QTL mapping was carried out to validate the genomic regions detected by QTL-seq and identify the epistatic interactions for PEDS in the $\mathrm{BC}_{3} \mathrm{~F}_{2}$ and $\mathrm{BC}_{4} \mathrm{~F}_{2}$ populations. Results from the study will enhance our understanding of the genetic basis of PEDS. 


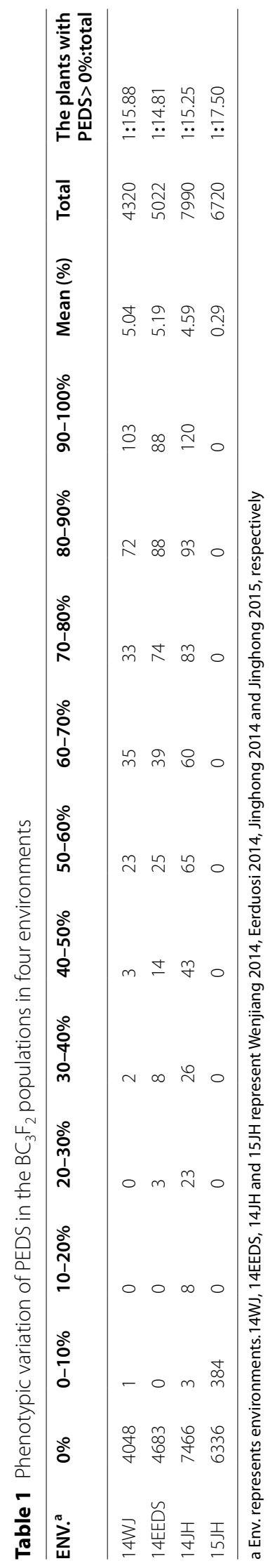




\section{Results}

\section{Phenotypic diversity in the $\mathrm{BC}_{3} \mathrm{~F}_{2}$ populations}

The ear of maize parent SICAU1212 has four rows (two ranks, two spikelets per cupule), whereas teosinte MT1 has two rows (two ranks, one spikelet per cupule). Therefore, the only difference is paired spikelets in SICAU1212 ear versus single spikelet in MT1 ear. The phenotypic variability of PEDS was high, ranging from $\mathrm{PEDS}=0$ (same as ear of SICAU1212) to PEDS $=100 \%$ (same as ear of MT1) in the $\mathrm{BC}_{3} \mathrm{~F}_{2}$ populations (Table 1 ; Fig. 1). The average PEDS of $\mathrm{BC}_{3} \mathrm{~F}_{2}$ populations were about $5.04,5.19,4.59$, and $0.29 \%$ in the 14WJ, 14EEDS, $14 \mathrm{JH}$ and $15 \mathrm{JH}$ environments. The ranges of PEDS variation were 0 to $100 \%$ in the $14 \mathrm{WJ}, 14 \mathrm{EEDS}$ and $14 \mathrm{JH}$ environments, but only 0 to $10 \%$ in the $15 \mathrm{JH}$ environment. The proportions of plants with PEDS $>0 \%$ were $1 / 15.88,1 / 14.81,1 / 15.25$, and $1 / 17.5$ in the four environments (Table 1). Notably, the frequency distributions were continuous variation (except in the $15 \mathrm{JH}$ environment) and did not follow normal distribution. Instead, they were dramatically skewed towards the maize phenotype (PEDS $=0 \%$ ) (Table 1 ), suggesting that PEDS may be a quantitatively inherited trait.

\section{Whole-genome resequencing, mapping of reads and identification of SNPs}

The six bulks and SICAU1212 were sequenced, and the whole-genome resequencing (WGRS) data were generated. A total of 117.17 million paired-end (PE) reads and $34.98 \mathrm{~Gb}$ of sequencing data were generated for SICAU1212. The alignment of the PE reads of SICAU1212 to the maize reference genome (B73-RefGen_v4) achieved $80.24 \%$ genome coverage and $15.21 \times$ read depth. For the five high PEDS bulks, the number of PE reads ranged from 293.47 to 293.92 million, and the sequencing data for them varied from 44.02 to $44.09 \mathrm{~Gb}$. For the low PEDS bulk, there were 294.18 million PE reads and $44.13 \mathrm{~Gb}$ of sequencing data (Table S1). In the case of high PEDS bulks, mapping of reads to the maize reference genome (B73-RefGen_v4) resulted in $81.43-85.12 \%$ coverage and $19.14 \times-19.17 \times$ read depth. Similarly, in the low PEDS bulk, there was $83.34 \%$ coverage and $19.18 \times$ read depth (Table S1). In total, 23,825,847, 24,139,555, 23,686,654, $23,849,835,23,550,026$, and 23,826,344 SNPs were identified for HP1-bulk, HP2-bulk, HP3-bulk, HP4bulk, HP5-bulk, and LP-bulk, respectively. Among them, 4,224,921, 1,778,418,4,867,842, 4,964,187, and 2,052,270 polymorphic SNPs were detected between HP1-bulk and LP-bulk, HP2-bulk and LP-bulk, HP3bulk and LP-bulk, HP4-bulk and LP-bulk, and HP5bulk and LP-bulk, respectively.

\section{Candidate genomic regions associated with PEDS}

To identify candidate genomic regions associated with PEDS, the SNP-index was estimated individually in each bulk and $\Delta$ (SNP-index) was calculated, and the corresponding graphs were plotted against the genome positions (Fig. S2). Generally speaking, the SNP-index graphs between high and low bulks would be identical for the genomic regions that are not relevant to the phenotypic difference, while they should exhibit unequal contributions from the two parental genomes if the genomic region harboring QTL contributed to the difference in the phenotype $[25,32]$. Based on the graphs of SNP-index of bulks in Fig. 2, the SNP-indices in the regions on chromosome 1 from $194.64 \mathrm{Mb}$ to $299.52 \mathrm{Mb}$, chromosome 3 from $0 \mathrm{Mb}$ to $162.80 \mathrm{Mb}$, chromosome 6 from $12.82 \mathrm{Mb}$ to $97.17 \mathrm{Mb}$, and chromosome 8 from $125.06 \mathrm{Mb}$ to $157.01 \mathrm{Mb}$ were larger in high bulks than the low bulk in the 14EEDS and 14J $\mathrm{J}$ environments, but not in the $15 \mathrm{JH}$ environment, suggesting that these regions probably contained QTL responsible for PEDS. In contrast, the SNP-indices of the remaining chromosomes were near 0 , indicating that these chromosomes were rich in alleles from the maize parent SICAU1212.

Combining the SNP-index and $\Delta$ (SNP-index) values, at $95 \%$ significance level, three candidate genomic regions (seqPEDS3.1, seqPEDS3.2 and seqPEDS3.3) were identified for PEDS on chromosome 3, located on $42.22-44.05 \mathrm{Mb}, 52.13-52.58 \mathrm{Mb}$ and $119.6-119.78 \mathrm{Mb}$ in the HP2-bulk and LP-bulk test (Fig. 2B; Table 2). In all three regions, the alleles from teosinte parent MT1 increased PEDS value, whereas those from maize parent SICAU1212 decreased PEDS value. However, no significant candidate genome region was detected in other bulks tests.

\section{Validation of the genomic regions}

To validate the genomic regions detected by QTL-seq, the traditional QTL mapping was performed in the $\mathrm{BC}_{3} \mathrm{~F}_{2}$ population consisting of 280 and 333 plants from the $14 \mathrm{JH}$ and $18 \mathrm{WJ}$ environments, and the $\mathrm{BC}_{4} \mathrm{~F}_{2}$ population containing 651 plants from the $15 \mathrm{WJ}$ environment. In these populations, the frequency distributions did not follow a normal distribution, but were dramatically skewed to maize parent SICAU1212 (Fig. S3). Firstly, 74 markers (1 SSR and $73 \mathrm{InDel}$ ) were selected to check polymorphism between parents. Then, the polymorphic markers were utilized to genotype $36 \mathrm{~F}_{2}$ plants. Finally, 31 polymorphic and no distorted segregation markers [including 8 markers on chromosome 1, 14 markers on chromosome 3, 4 markers on chromosome 6 , and 5 markers on chromosome 8 (Table S2)] were used to genotype the $\mathrm{BC}_{3} \mathrm{~F}_{2}$ and $\mathrm{BC}_{4} \mathrm{~F}_{2}$ populations. The local genetic 

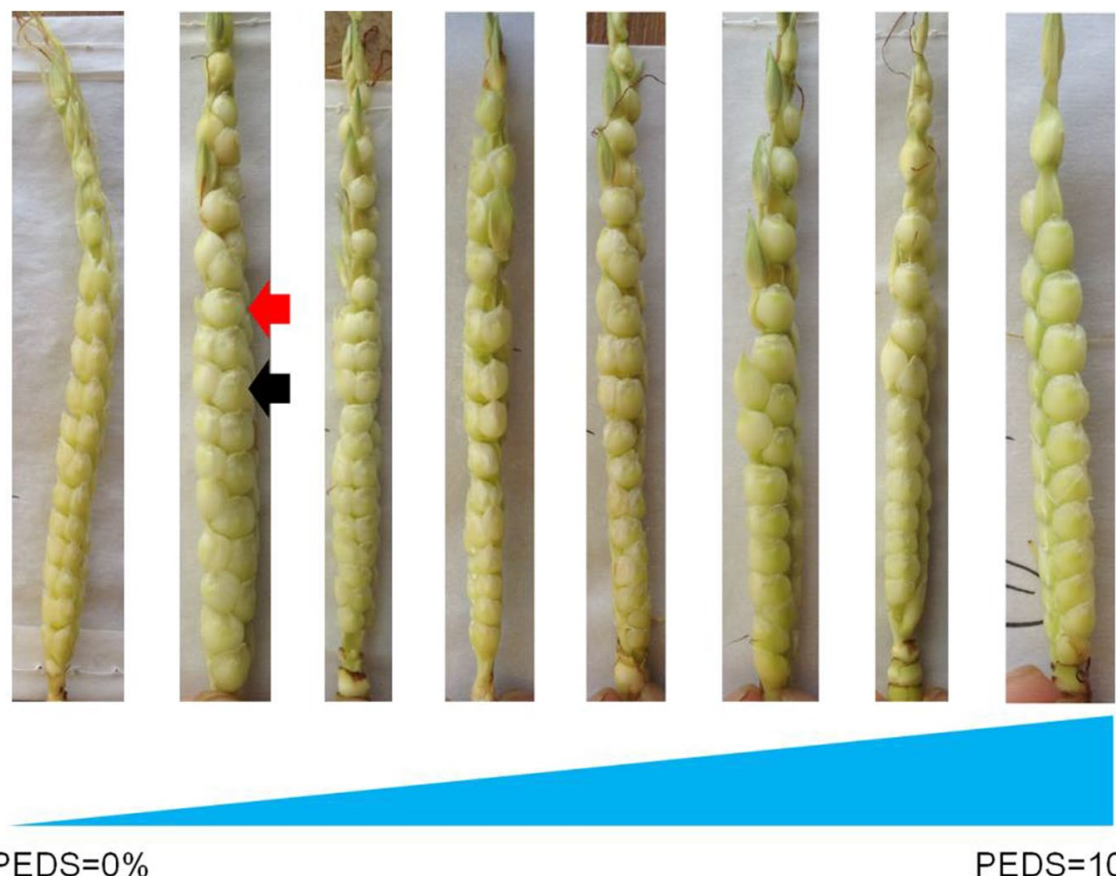

\section{PEDS $=100 \%$}

Fig. 1 Ears of the plants selected from the $\mathrm{BC}_{3} \mathrm{~F}_{2}$ population. The red arrow points to single spikelet, and black arrow points to paired spikelet. PEDS $=0 \%$ indicates that all cupules of the ear show paired spikelets, and PEDS $=100 \%$ indicates that all cupules of the ear show single spikelet

linkage maps were constructed for the candidate genomic regions on chromosomes $1,3,6$, and 8 (Fig. 3).

Using the local genetic linkage maps and the phenotyping data, two and two QTL related to PEDS were identified in the $\mathrm{BC}_{3} \mathrm{~F}_{2}$ population in $14 \mathrm{WJ}$ and $18 \mathrm{WJ}$ environments, and five $\mathrm{QTL}$ in the $\mathrm{BC}_{4} \mathrm{~F}_{2}$ population in $15 \mathrm{WJ}$ environment, located on chromosomes 1, 3, 6 and 8 (Table 3; Fig. 3). The phenotypic variance explained (PVE) of individual QTL ranged from 1.12 to $38.05 \%$. Notably, the QTL qPEDS3.1 (a major and stably expressed QTL) explained 33.91-38.05\% of the phenotypic variance identified in all three environments. The additive effect of $q P E D S 3.1$ was negative, suggesting that the alleles from teosinte parent MT1 increased the value of PEDS. The consistent QTL qPEDS1.1 and qPEDS6.1 accounted for $1.12-7.15 \%$ of the phenotypic variance in two environments. The QTL qPEDS1.2 and qPEDS8.1 with $P V E=1.12-1.82 \%$ were only mapped in the $\mathrm{BC}_{4} \mathrm{~F}_{2}$ population in $15 \mathrm{WJ}$ environment. In summary, the QTL mapping results supported that there were QTL for
PEDS in the candidate genomic regions on chromosomes 1, 3, 6 and 8 identified by QTL-seq.

Five, seven and five pairs of epistatic QTL were detected in the $\mathrm{BC}_{3} \mathrm{~F}_{2}$ population in the $14 \mathrm{WJ}$ and $18 \mathrm{WJ}$ environments, and the $\mathrm{BC}_{4} \mathrm{~F}_{2}$ population in the $15 \mathrm{WJ}$ environment, respectively (Table 4; Fig. 4). The PVE of individual epistatic QTL ranged from 3.85 to $21.31 \%$; the total PVE of all the epistatic QTL varied from 45.81 to $66.81 \%$, being larger than those of all the QTL mentioned above in each environment. However, there were two kinds of epistatic QTL [33]. One was that additive by additive effect was positive, increasing the expression of PEDS and explaining 56.85, 34.57 and $18.71 \%$ of phenotypic variation in each test, whereas the other was negative, decreasing the expression of PEDS and explaining $9.96,11.23$ and $28.85 \%$ of phenotypic variation.

\section{Investigation of PEDS in the near-isogenic lines (NILs)}

For each QTL related to PEDS identified by the traditional QTL mapping, NILs were developed through

(See figure on next page.)

Fig. 2 Four candidate genomic regions associated with PEDS identified by QTL-seq. A HP1-bulk vs. LP-bulk, B HP2-bulk vs. LP-bulk, C HP3-bulk vs. LP-bulk, and D HP4-bulk vs. LP-bulk. X-axis represents the position of chromosome (Mb) and Y-axis represents the SNP-index or $\triangle$ (SNP-index). The light green lines represent the SNP-index of low PEDS bulks, the orange lines represent the SNP-index of high PEDS bulks; the blue lines represent the $\Delta$ (SNP-index), the red lines represent the threshold values under the null hypothesis at significant level $P<0.05$, and the green lines represent the threshold values under the null hypothesis at significant level $P<0.01$ 

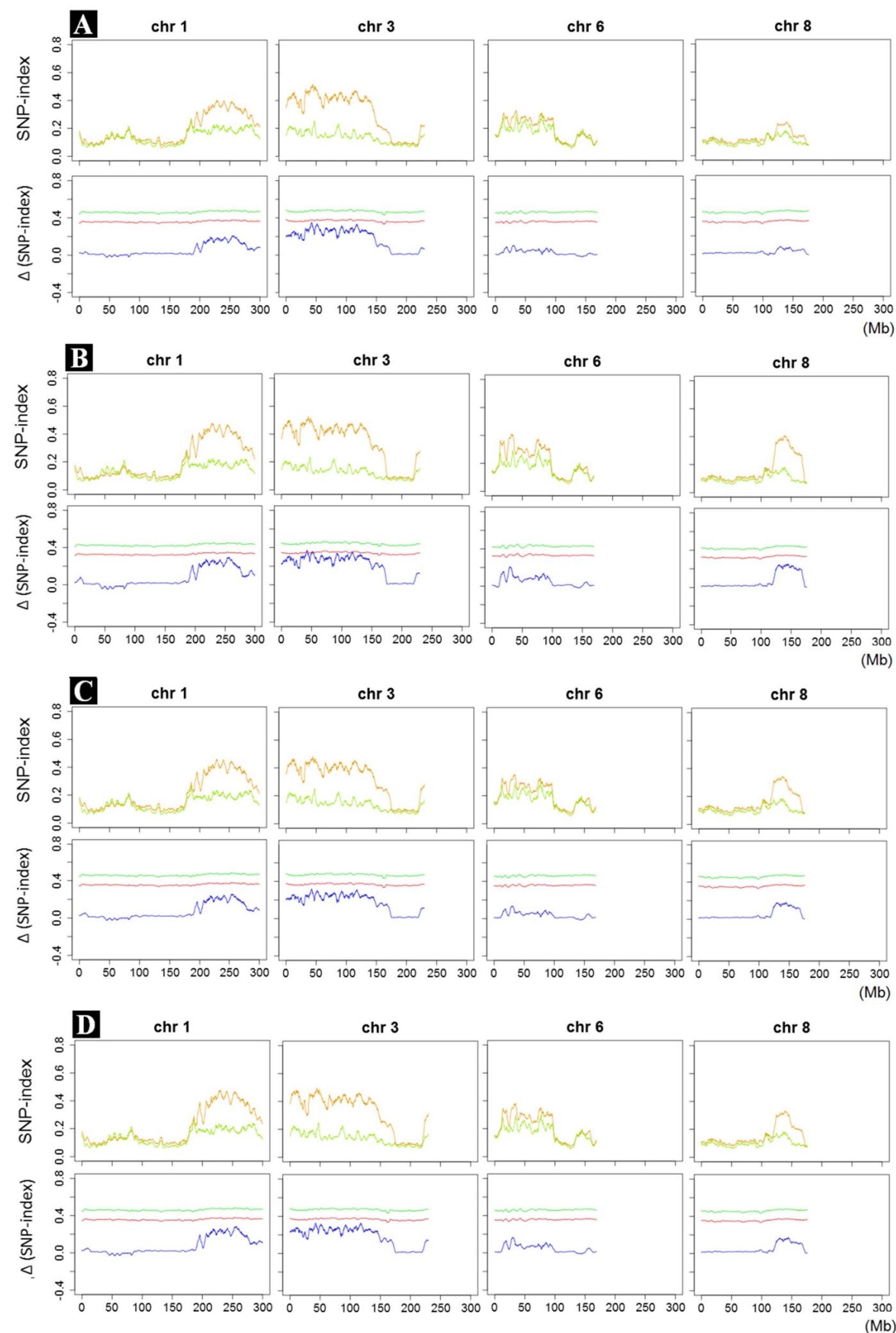

(Mb)
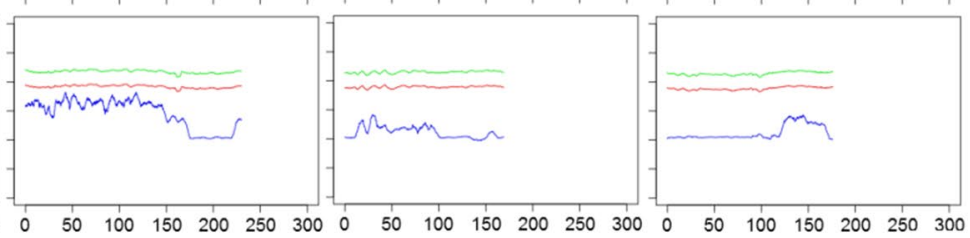

Fig. 2 (See legend on previous page.) 
Table 2 Significant genomic regions for PEDS identified by QTL-seq

\begin{tabular}{|c|c|c|c|c|c|}
\hline Bulks & QTL & Chromosome & Physical interval $(\mathrm{Mb})^{\mathrm{a}}$ & $\Delta$ (SNP-index) range & Significant level \\
\hline \multirow{3}{*}{$\begin{array}{l}\text { HP2-bulkVS.LP- } \\
\text { bulk }\end{array}$} & seqPEDS3.1 & 3 & $42.22-44.05$ & $0.35-0.37$ & $p<0.05$ \\
\hline & seqPEDS3.2 & 3 & $52.13-52.58$ & $0.35-0.36$ & $p<0.05$ \\
\hline & seqPEDS3.3 & 3 & 119.6-119.78 & $0.35-0.36$ & $p<0.05$ \\
\hline
\end{tabular}

${ }^{a}$ Physical position is based on B73-RefGen_V4 sequence

selecting the plants with the MT1 alleles in the target QTL regions and the SICAU1212 alleles in other QTL regions in the $\mathrm{BC}_{4} \mathrm{~F}_{2}$ population mentioned above, designated as NIL-qPEDS1.1(MT1), NIL-qPEDS3.1(MT1), NIL-qPEDS6.1(MT1), and NIL-qPEDS8.1(MT1). Two families of each NIL with 16-21 plants were grown at Jinghong city, Yunnan province, in September 2015, and the parent SICAU1212 was used as CK. In the NIL-qPEDS1.1(MT1), two out of 16 plants in one family showed PEDS $>0$, with the average PEDS of $6.91 \%$, but the PEDS of all 18 plants in another family were 0 (Table 5). In the NIL-qPEDS3.1(MT1), three and one plants showed PEDS $>0$ in the two families with 18 plants, with the average PEDS of 31.43 and $32.14 \%$. However, the PEDS of all plants in the NIL-qPEDS6.1(MT1) and NIL-qPEDS8.1(MT1) were 0. Notably, the flowering times of plants of NIL-qPEDS8.1(MT1) were $\sim 7$ days earlier compared with SICAU1212. These results indicated that the ratio of plant with PEDS $>0$ was low $(1 / 18-3 / 18)$ or 0 in each NIL, which was not conducive to fine mapping of QTL.

\section{Discussion}

The two-ranked maize parent SICAU1212 was helpful for accurate identification of PEDS

Single vs. paired spikelets (PEDS) is one of the key domesticated traits. The single spikelets of teosinte ears were totally transformed into paired spikelets of maize ears during maize domestication. However, little is known about the genetic basis of this transformation of single into paired spikelets. Understanding the genetic basis of PEDS is helpful for the map-based gene cloning. In the present study, a primitive four rows (two ranks) waxy maize inbred line (SICAU1212) was used as a female parent to develop the advanced mapping populations $\left(\mathrm{BC}_{3} \mathrm{~F}_{2}\right.$ and $\left.\mathrm{BC}_{4} \mathrm{~F}_{2}\right)$. SICAU1212 is similar to the primitive maize of 6000 years ago in phenotypic traits, including small plant, multiple ears, rachis from the ears, 4-row ears and tens of grains [34, 35]. Notably, both the SICAU1212 and teosinte MT1 ears were two ranks, and the ears of all plants in the segregating population of SICAU1212 $\times$ MT1 showed only two ranks, thus avoiding a possible confusion about the importance of the single spikelet vs. a decrease in the rank number in multi-rank ears. Therefore, the phenotype of PEDS was investigated more accurately, especially at the silking stage, which was essential for the QTL mapping.

\section{Comparison of QTL for PEDS in this study with those in previous studies}

Four candidate genomic regions associated with PEDS located on chromosomes $1,3,6$, and 8 were identified using QTL-seq, followed by detecting the QTL for PEDS in each candidate genomic region by traditional QTL mapping. The QTL qPEDS1.1 identified in this study overlapped with the QTL flanked by umc11-umc83 and umc37b mapped by Doebley et al. [12, 13], because they were all located at $184-258 \mathrm{Mb}$ of chromosome 1 . The QTL (QTL-1L) accounting for $\sim 19.5 \%$ of phenotypic variance was identified repeatedly in the previous studies $[7,13,15]$, near to the gene teosinte branched1 (tb1) [15, $36]$, which was included in the QTL qPEDS1.2. According to the results of QTL-seq, the region of $0-173 \mathrm{Mb}$ on chromosome 3 was associated with PEDS variation; however, only one QTL qPEDS3.1 explaining 33.91-38.05\% of phenotypic variance was identified in the $\mathrm{BC}_{3} \mathrm{~F}_{2}$ and $\mathrm{BC}_{4} \mathrm{~F}_{2}$ populations by traditional QTL mapping, possibly near to QTL (umc121-umc92 and umc32) mapped by Doebley et al. $[7,14]$. The QTL qPEDS3.1 may be a novel major and stably expressed QTL, and it is worthy of further study. In addition, QTL (QTL-3L) was identified repeatedly in the previous studies $[12,13,15]$, located at $\sim 181 \mathrm{Mb}$ on chromosome 3. However, no QTL for PEDS was identified near this region, probably the InDel markers used in this study did not contain this region, with the farthest InDel marker (PM16) being located at $\sim 157 \mathrm{Mb}$ on chromosome 3 . It is interesting that the region of $0-173 \mathrm{Mb}$ on chromosome 3 was completely retained in the $\mathrm{BC}_{3} \mathrm{~F}_{2}$ population developed by phenotypic recurrent selection for PEDS, inferring that several QTL related to PEDS located in this region may not be identified. Although one QTL (umc85-umc65) for PEDS located on chromosome 6 was mapped [12], we do not know how far away it is from the minor QTL qPEDS6.1 that explained $1.12-3.26 \%$ of phenotypic variance because the physical positions of markers umc 85 and umc65 could not be found. The QTL qPEDS8.1 on chromosome 
$\mathbf{A}$

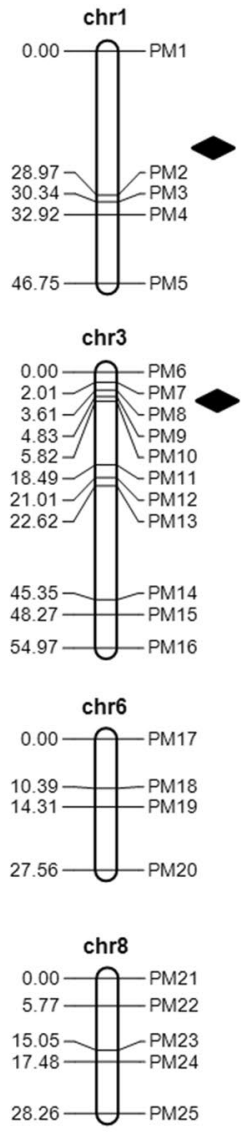

B

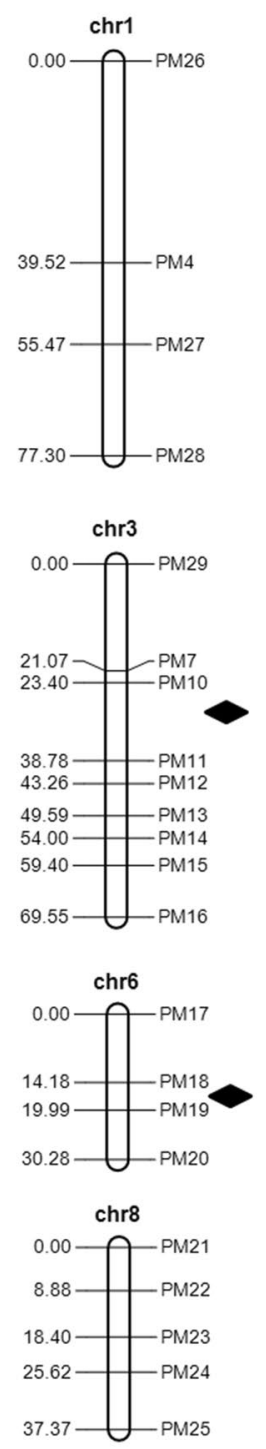

C

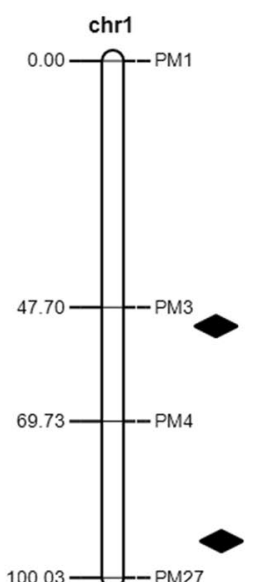

chr3

5.00-ी -

$5.17>-\mathrm{PM} 30$

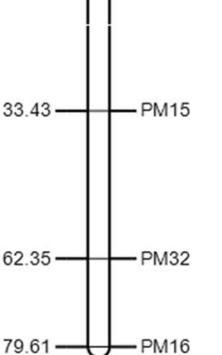

chr6

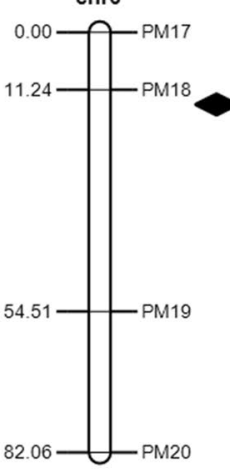

chr8

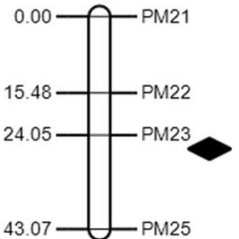

Fig. 3 The local genetic linkage maps of $\mathrm{BC}_{3} \mathrm{~F}_{2}$ and $\mathrm{BC}_{4} \mathrm{~F}_{2}$ populations in three environments. $\mathbf{A}$ The $\mathrm{BC}_{3} \mathrm{~F}_{2}$ population in the $14 \mathrm{JH}$ environment, $\mathbf{B}$ The $\mathrm{BC}_{3} \mathrm{~F}_{2}$ population in the $18 \mathrm{WJ}$ environment, and $\mathbf{C}$ The $\mathrm{BC}_{4} \mathrm{~F}_{2}$ population in the $15 \mathrm{WJ}$ environment. Genetic distances (cM) are shown on the left and markers are indicated on the right. The diamonds represent QTL for PEDS 
Table 3 Significant QTL for PEDS in the $\mathrm{BC}_{3} \mathrm{~F}_{2}$ and $\mathrm{BC}_{4} \mathrm{~F}_{2}$ populations by traditional QTL mapping

\begin{tabular}{|c|c|c|c|c|c|c|c|c|c|}
\hline Population & Env. $^{\text {a }}$ & QTL & Chromosome & Marker interval & Physical interval $(\mathrm{Mb})^{\mathbf{b}}$ & $\operatorname{LOD}^{c}$ & PVE (\%) ${ }^{d}$ & Add & Dom \\
\hline \multirow[t]{4}{*}{$\mathrm{BC}_{3} \mathrm{~F}_{2}$} & \multirow[t]{2}{*}{$14 \mathrm{JH}$} & aPEDS1.1 & 1 & PM1-PM2 & $184.63-222.02$ & 5.88 & 7.15 & -0.08 & 0.07 \\
\hline & & qPEDS3.1 & 3 & PM7-PM8 & $10.86-12.56$ & 34.81 & 38.05 & -0.18 & -0.2 \\
\hline & \multirow[t]{2}{*}{$18 \mathrm{WJ}$} & qPEDS3.1 & 3 & PM10-PM1 1 & $14.12-39.65$ & 52.97 & 33.92 & -0.34 & -0.24 \\
\hline & & qPEDS6.1 & 6 & PM18-PM19 & $75.43-83.98$ & 3.23 & 1.12 & -0.04 & -0.08 \\
\hline \multirow[t]{5}{*}{$\mathrm{BC}_{4} \mathrm{~F}_{2}$} & \multirow[t]{5}{*}{$15 \mathrm{WJ}$} & qPEDS1.1 & 1 & PM3-PM4 & $230.13-258.06$ & 5.04 & 1.25 & 0.04 & -0.05 \\
\hline & & QPEDS1.2 & 1 & PM4-PM27 & 258.06-281.12 & 3.98 & 1.12 & -0.06 & -0.01 \\
\hline & & qPEDS3.1 & 3 & PM30-PM10 & $11.89-14.12$ & 31.17 & 33.91 & -0.14 & -0.14 \\
\hline & & qPEDS6.1 & 6 & PM18-PM19 & $75.43-83.98$ & 8.2 & 3.26 & 0.07 & -0.03 \\
\hline & & qPEDS8.1 & 8 & PM23-PM25 & $126.24-149.80$ & 4.69 & 1.82 & -0.05 & 0.03 \\
\hline
\end{tabular}

${ }^{a}$ Env. represents environments.14JH, 18WJ and 15WJ represent Jinghong 2014, Wenjiang 2018 and Wenjiang 2015, respectively

${ }^{\text {b }}$ Physical position is based on B73-RefGen_V4 sequence

cLOD score

${ }^{d}$ Phenotypic variance explained by each QTL

$8 \mathrm{~L}$ identified in this study may be close to the locus $p d 2$ related to PEDS mapped by Ve'ronique and Benjamin [9].

\section{Epistasis played a vital role in PEDS variation}

Five to seven epistatic QTL with the total PVE of 47.57$66.81 \%$ were identified in each test, which was more than the effect of main QTL (35.02-47.12\%). Deobley at el. (1993, 1995) identified significant epistasis between QTL-1 L (umc107) and QTL-3L (umc92); the effect of each QTL was much lower in the advanced background population than the $F_{2}$ population, with the combined effect of two QTL decreasing about 10-fold [13, 15]. No significant epistatic QTL between QTL-1L and QTL-3L was detected in this study; comparatively, one locus of EPqpeds-1 was included the region of QTL-1L, one locus of EPqpeds-6 was close to QTL-1 L, and one locus of EPqpeds-11 was near QTL-3L. Notably, one locus of epistatic QTL EPqpeds-2, EPqpeds-3, EPqpeds-4, EPqpeds-5, EPqpeds-7, and EPqpeds-13 overlapped with, or was close to, the major QTL qPEDS3.1 (Table 5); another locus was located on chromosomes $1,3,6$, and 8 , suggesting that the epistatic interactions between qPEDS3.1 and other loci were very strong, partly explaining the very low ratio of PEDS $>0$ in the NIL-qPEDS3.1(MT1) families as well as in the other NILs of QTL. Moreover, 50 pairs of epistatic QTL were identified on 10 chromosomes, explaining $94.40 \%$ of the total phenotypic variance in the $\mathrm{F}_{2}$ population of SICAU1212 $\times$ MT1 (unpublished data). The number and effect of epistatic QTL identified in the $\mathrm{BC}_{3} \mathrm{~F}_{2}$ and $\mathrm{BC}_{4} \mathrm{~F}_{2}$ populations decreased significantly, inferring that the advanced mapping population developed by phenotypic recurrent selection for PEDS eliminated partly the effect of epistasis. Taken together, the epistasis played a key role in PEDS variation. Unfortunately, the impact of epistasis was neglected in fine mapping or positional cloning of QTL/gene for complex traits such as PEDS [37]. For fine mapping of the major QTL qPEDS3.1, the two, three and four QTL will be combined to evaluate the effect; then, the residual heterozygous lines of $q P E D S 3.1$ will be developed in future research by selecting the heterozygous alleles in the region of $q P E D S 3.1$ and the homozygous alleles in other regions of QTL $[38,39]$.

\section{Photoperiod significantly affect the expression of single spikelet}

The photoperiod-related trait is a primary domestication trait in maize. The geographic range of maize has rapidly expanded from tropical to temperate regions due to the loss of photoperiod sensitivity $[40,41]$. The effects of photoperiod on tassel branches and the number of anthers were reported by Bechoux et al. [42]. Boden et al. suggested that Photoperiod-1 (Ppd-1) responsible for flowering time has a significant inhibitory effect on paired spikelet formation [43]. In the present study, the expression of PEDS decreased significantly, and no genomic region for PEDS was identified in the $15 \mathrm{JH}$ environment using QTL-seq (Fig. S2E). Compared to the other three environments, the day length was $11.20 \mathrm{~h}$ in the seedling stage and $11.73 \mathrm{~h} 1$ month later in the $15 \mathrm{JH}$ environment, which was shorter than $12.53 \mathrm{~h}$ in the $14 \mathrm{WJ}$ environment, $14.97 \mathrm{~h}$ in the 14EEDS environment, and $12.85 \mathrm{~h}$ in the $14 \mathrm{JH}$ environment. The QTL qPEDS8.1 was mapped on chromosome 8 , which contained the gene $Z C N 8$ involved in photoperiod sensitivity of tropical maize [44]. Investigation of NIL-qPEDS8.1(MT1) planted at Jinghong city, Yunnan province, in September 2015, revealed that the teosinte allele had a shorter flowering time (by about 7 days) than that of SICAU1212. However, the presence of single spikelet was not confirmed. In 


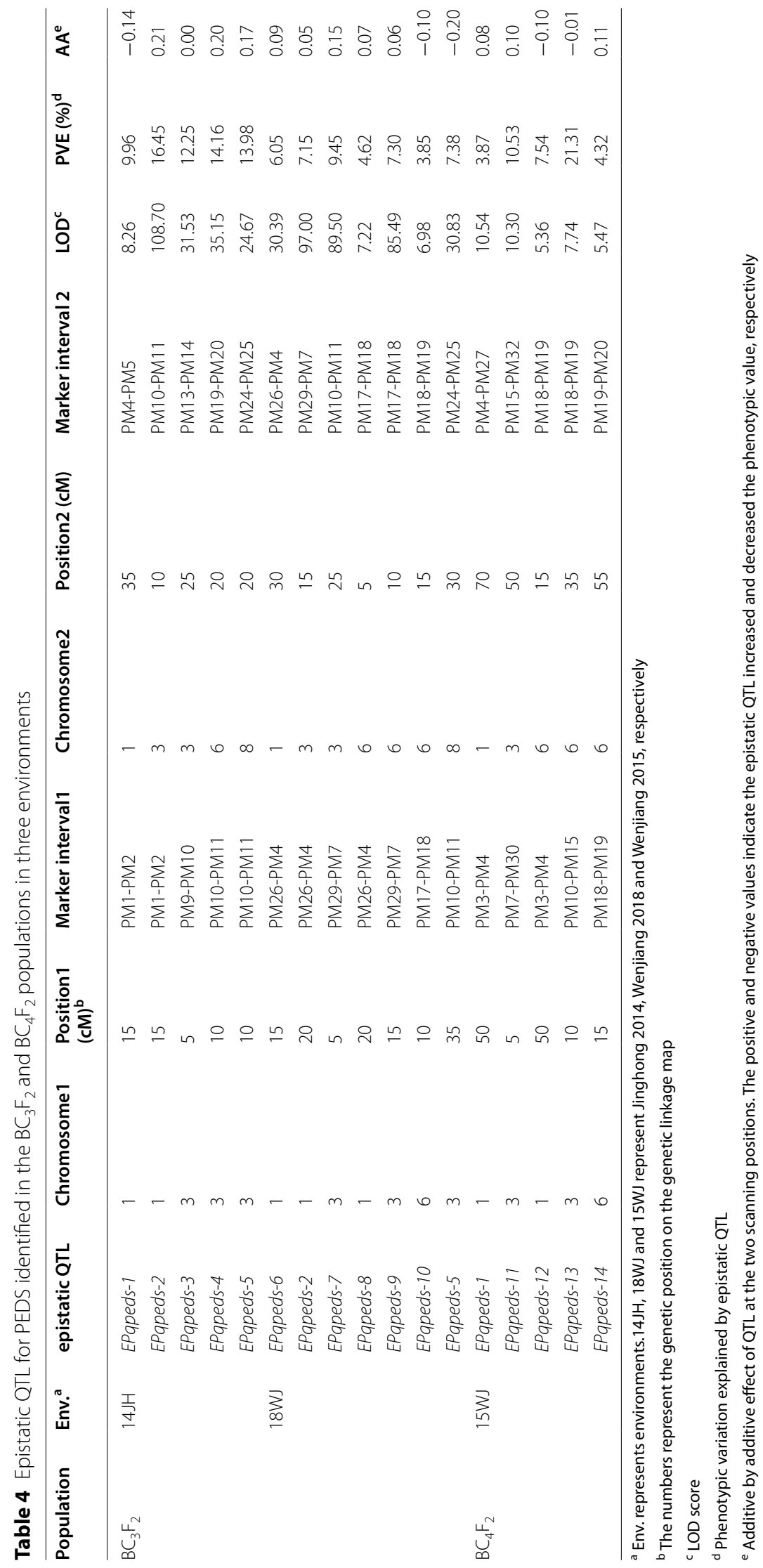



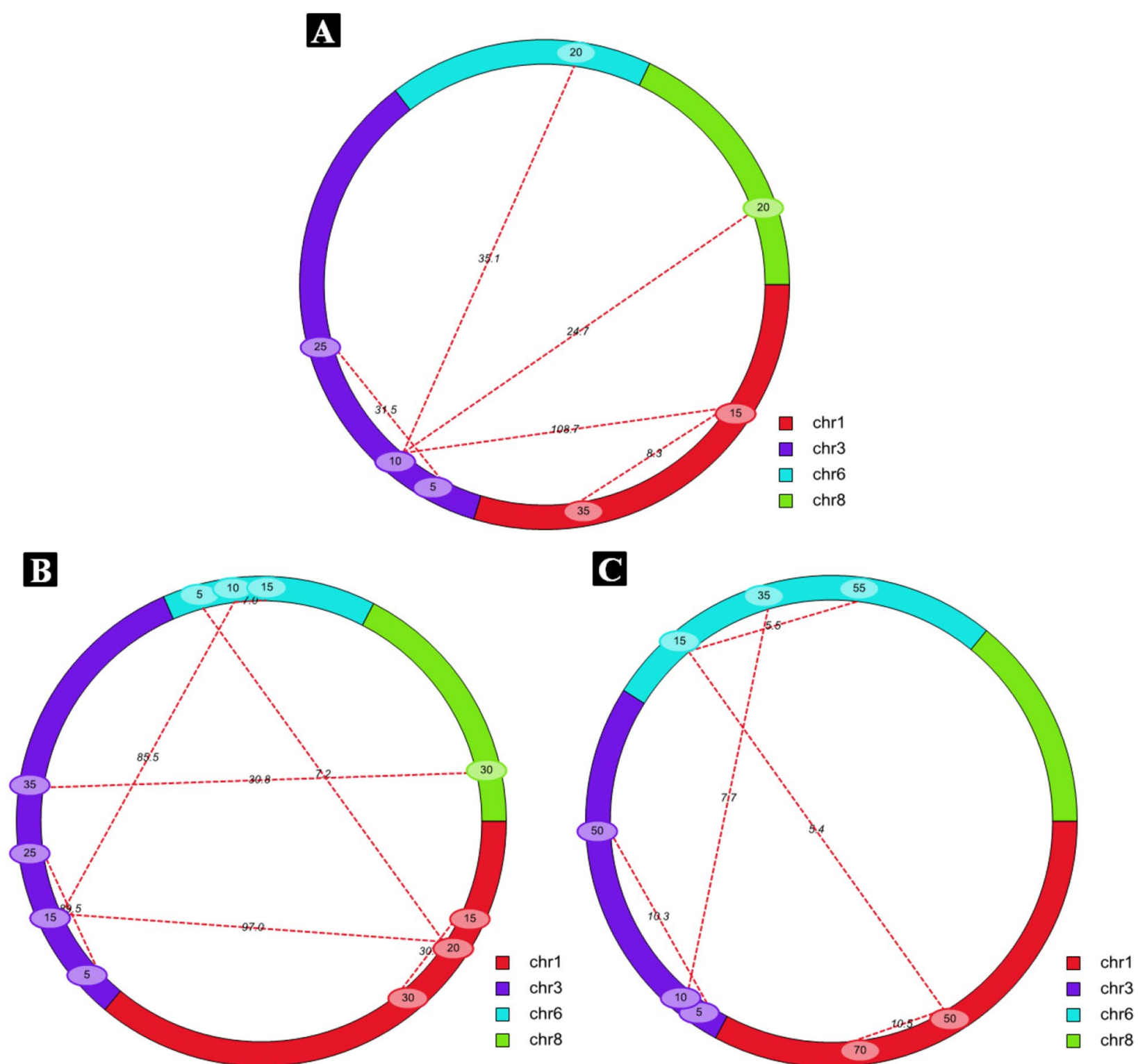

Fig. 4 Distribution of epistatic QTL for PEDS identified by $I C I M$ in the $B C_{3} F_{2}$ and $B C_{4} F_{2}$ populations in three environments. $A$ The $B C_{3} F_{2}$ population in the $14 \mathrm{JH}$ environment, $\mathbf{B}$ The $\mathrm{BC}_{3} \mathrm{~F}_{2}$ population in the $18 \mathrm{WJ}$ environment, and $\mathbf{C}$ The $\mathrm{BC}_{4} \mathrm{~F}_{2}$ population in the $15 \mathrm{WJ}$ environment. The red long dashed lines attached to the two loci involved in epistatic interaction for PEDS, the numerical values in the colorized circle represent the genetic position on the linkage group, and the numbers on the dashed lines show the LOD values of the corresponding epistatic interactions

summary, the results inferred that photoperiod played an important role in the transformation of single into paired spikelets during maize domestication.

\section{Conclusion}

In the present study, to accurately investigate single and paired spikelets, a two-ranked maize were chosen to cross to teosinte to develop the advanced mapping populations (BC3F2 and BC4F2). Four candidate genomic regions associated with PEDS were identified on chromosomes 1, 3, 6 and 8 using QTL-seq. One major QTL, four minor QTL and 14 epistatic QTL for PEDS were detected in these four genomic regions by linkage map analysis. The expression of single spikelet was very low (PEDS $<10 \%$ ) in the $15 \mathrm{JH}$ environment, maybe due to the shorter day length compared to that in the other environments. The flowering time of plants of NILqPEDS8.1(MT1) was $\sim 7$ days shorter than that of "parent SICUAN1212". Taken together, these findings suggested that major QTL, minor QTL, epistasis, and photoperiod 
Table 5 Investigation of PEDS in the NILS of QTL

\begin{tabular}{|c|c|c|c|c|c|c|c|}
\hline \multirow[t]{2}{*}{ NILs } & \multicolumn{4}{|c|}{ Genotypes of the NILs ${ }^{a}$} & \multirow{2}{*}{$\begin{array}{l}\text { Number of } \\
\text { plants }\end{array}$} & \multirow{2}{*}{$\begin{array}{l}\text { Number of plants } \\
\text { with PEDS }>0\end{array}$} & \multirow[t]{2}{*}{ PEDS $(\%)^{b}$} \\
\hline & qPEDS1.1 & qPEDS3.1 & qPEDS6.1 & qPEDS8.1 & & & \\
\hline NIL-qPEDS1.1-1 & MT1 & SICAU1212 & SICAU1212 & SICAU1212 & 16 & 2 & 6.91 \\
\hline NIL-qPEDS1.1-2 & MT1 & SICAU1212 & SICAU1212 & SICAU1212 & 18 & 0 & 0 \\
\hline NIL-qPEDS3.1-1 & SICAU1212 & MT1 & SICAU1212 & SICAU1212 & 18 & 3 & 31.43 \\
\hline NIL-qPEDS3.1-2 & SICAU1212 & MT1 & SICAU1212 & SICAU1212 & 18 & 1 & 32.14 \\
\hline NIL-qPEDS6.1-1 & SICAU1212 & SICAU1212 & MT1 & SICAU1212 & 16 & 0 & 0 \\
\hline NIL-qPEDS6.1-2 & SICAU1212 & SICAU1212 & MT1 & SICAU1212 & 17 & 0 & 0 \\
\hline NIL-qPEDS8.1-1 & SICAU1212 & SICAU1212 & SICAU1212 & MT1 & 16 & 0 & 0 \\
\hline NIL-qPEDS8.1-2 & SICAU1212 & SICAU1212 & SICAU1212 & MT1 & 21 & 0 & 0 \\
\hline
\end{tabular}

${ }^{a}$ MT1 represent the alleles come from the teosinte parent MT1 and SICAU1212 represent the alleles come from the maize parent SICAU1212

${ }^{b}$ The value is the average of PEDS of plants with PEDS $>0$

were associated with the transformation of single spikelet in teosinte ears into paired spikelets in maize ears during maize domestication, providing insights into the genetic basis of PEDS and an opportunity to fine map major QTL for PEDS in the future work.

\section{Materials and methods}

\section{Plant materials and development of the advanced} mapping populations

The maize inbred line SICAU1212 and teosinte MT1 (Z. mays ssp. mexicana) were used as parental lines to develop the advanced segregating populations for PEDS. SICAU1212 was derived from a waxy maize landrace Silunuo $[45,46]$ and is owned by our lab; it has two ranks with two spikelets per cupule. MT1 was obtained from the International Maize and Wheat Improvement Center (CIMMYT) (accession number 11394); it has two ranks with one spikelet per cupule. A cross was made between SICAU1212 and MT1 to create $F_{1}$ in April 2010; $F_{1}$ was self-pollinated to develop the $F_{2}$ population in October 2010. The plants with PEDS $=100 \%$ (exclusively singe spikelet) were selected from the $\mathrm{F}_{2}$ population to backcross to SICAU1212 to create $\mathrm{BC}_{1} \mathrm{~F}_{1}$ in April 2011; then, $\mathrm{BC}_{1} \mathrm{~F}_{1}$ was self-pollinated to develop the $\mathrm{BC}_{1} \mathrm{~F}_{2}$ population in October 2011. Again, the plants with PEDS $=100 \%$ were chosen from the $B_{1} F_{2}$ to backcross to SICAU1212 to create $\mathrm{BC}_{2} \mathrm{~F}_{1}$ in April 2012; $\mathrm{BC}_{2} \mathrm{~F}_{1}$ was self-pollinated to develop the $\mathrm{BC}_{2} \mathrm{~F}_{2}$ population in October 2012. The procedure mentioned above had been performed repeatedly, until the $\mathrm{BC}_{4} \mathrm{~F}_{2}$ population was developed in October 2014 (Fig. S1).

\section{Field experiments and evaluation of PEDS}

To investigate the phenotypic values, the $\mathrm{BC}_{3} \mathrm{~F}_{2}$ population was grown in five experimental environments, including 4320 plants at Wenjiang district, Sichuan province, in April $2014\left(14 \mathrm{WJ}, 30^{\circ} 40^{\prime} \mathrm{N}, 104^{\circ} 04^{\prime} \mathrm{E}\right.$, altitude $750 \mathrm{~m}$, average high / low temperature of $23^{\circ} \mathrm{C} /$ $14^{\circ} \mathrm{C}$ in April and $26^{\circ} \mathrm{C} / 17^{\circ} \mathrm{C}$ in May), 5022 plants at Eerduosi city, Neimenggu autonomous region, in June 2014 (14EEDS, $40.04^{\circ} \mathrm{N}, 110.01^{\circ} \mathrm{E}$, altitude $1015 \mathrm{~m}$, average high / low temperature of $25^{\circ} \mathrm{C} / 15^{\circ} \mathrm{C}$ in June and $26^{\circ} \mathrm{C} / 17^{\circ} \mathrm{C}$ in July); 7990 plants at Jinghong city, Yunnan province, in August $2014\left(14 \mathrm{JH}, 22^{\circ} 01^{\prime} \mathrm{N}, 100^{\circ} 58^{\prime} \mathrm{E}\right.$, altitude $551 \mathrm{~m}$, average high / low temperature of $31^{\circ} \mathrm{C}$ $/ 22^{\circ} \mathrm{C}$ in August and $32^{\circ} \mathrm{C} / 22^{\circ} \mathrm{C}$ in September); 6720 plants at Jinghong city, Yunnan province, in January 2015 $\left(15 \mathrm{JH}\right.$, average high / low temperature of $25^{\circ} \mathrm{C} / 11^{\circ} \mathrm{C}$ in January and $28^{\circ} \mathrm{C} / 13^{\circ} \mathrm{C}$ in February); and 350 plants at Wenjiang district, Sichuan province, in April 2018 (18WJ, average high / low temperature of $25^{\circ} \mathrm{C} / 14^{\circ} \mathrm{C}$ in April and $27^{\circ} \mathrm{C} / 17^{\circ} \mathrm{C}$ in May). The $\mathrm{BC}_{4} \mathrm{~F}_{2}$ population of 700 plants was grown at Wenjiang district, Sichuan province, in April 2015 (15WJ, average high / low temperature of $24^{\circ} \mathrm{C} / 14^{\circ} \mathrm{C}$ in April and $28^{\circ} \mathrm{C} / 18^{\circ} \mathrm{C}$ in May).

The presence (paired spikelets)/absence (single spikelet) of the pedicellate spikelet in each cupule can vary among cupules within a single ear; therefore, PEDS was recorded as percentage of cupules without a pedicellate spikelet $[7,12]$. For ease and accuracy, single and paired spikelets were counted on the basal-most secondary lateral inflorescence when the plant had silks visible. The cubic root transformations of phenotype data were carried out to reduce skewness and kurtosis because the PEDS distribution of $\mathrm{BC}_{3} \mathrm{~F}_{2}$ populations did not follow a normal distribution [12]. The descriptive statistics of the populations were analyzed using SPSS19.0 software (http://www.spss.com).

\section{Construction of bulks}

Extreme bulks were prepared for PEDS based on precise phenotyping. Six extreme bulks were constructed as 
follows: 50 plants with PEDS $>90 \%$ were selected from the $\mathrm{BC}_{3} \mathrm{~F}_{2}$ population in the 14EEDS environment to constitute high PEDS bulk (HP1-bulk). One hundred plants with PEDS $>90 \%$ were chosen from the $\mathrm{BC}_{3} \mathrm{~F}_{2}$ population in the $14 \mathrm{JH}$ environment (numbered Y1 to Y100). Three high PEDS bulks were constructed with 25 common plants (Y1-Y25) plus 25 additional plants (Y26-Y50, Y51-Y75, Y76-Y100). HP2-bulk comprised Y1-Y25 + Y26Y50, HP3-bulk was Y1-Y25+Y51-Y75, and HP4-bulk was made up of Y1-Y25+ Y76-Y100. Fifty plants with $0 \%<$ PEDS $\leq 10 \%$ were selected from the $\mathrm{BC}_{3} \mathrm{~F}_{2}$ population in the $15 \mathrm{JH}$ environment to create high PEDS bulk (HP5-bulk). Fifty plants with PEDS $=0 \%$ were chosen from the $\mathrm{BC}_{3} \mathrm{~F}_{2}$ population in the $14 \mathrm{JH}$ environment to construct the low PEDS bulk (LP-bulk).

\section{Construction of sequencing libraries and Illumina sequencing}

Genomic DNAs were extracted from the fresh leaves of individuals from the six bulks mentioned above and parent SICAU1212 by using the CTAB method [47]. DNA quality was evaluated using $1 \%$ agarose gel, and DNA concentration was quantified using a NanoDrop ${ }^{\circledR}$. The equimolar concentrations of DNA from individuals of each bulk were pooled together. To construct a library, two micrograms of DNA from each sample were first sheared using diagenode Bioruptor ${ }^{\circledR}$ NGS (Diogenode, Liege, Belgium) and then were subjected to end repair and adapter ligation. The size selection of libraries was performed using $2 \%$ agarose gel to get a target insert size of 500-600 bp. The libraries were purified first and then enriched using the adaptor-compatible PCR primers. The size distribution of amplified DNA libraries was checked on an Agilent Technologies 2100 Bioanalyzer using a High Sensitivity chip. The DNA libraries were sequenced on Illumina HiSeqTM 2000 to generate 150-base pairend reads [48-50].

\section{Calculation of SNP-index and $\Delta$ (SNP-index)}

After generating the sequences of all seven samples, the statistical analysis of the sequencing reads was conducted using the raspberry tool of NGS-QCbox [51]. The maize reference genome (B73-RefGen_v4) was downloaded from MaizeGDB (http://www.maizegdb. org/). The cleaned reads of each sample were aligned to B73-RefGen_v4 genome using the inbuilt BWA aligner [52], and the Coval software was used for post-processing and filtering of the alignment files [53]. The SNP-index as the proportion of short reads harboring SNPs that are different from the reference sequence $[25,54]$, was calculated for each bulk using the formula [24]: SNP-index (at a position $)=($ count of alternate base $) /($ count of reads aligned). To improve accuracy of SNPs, the SNP positions with read depth $<4 \times$ or $>32 \times$ were filtered out because these SNPs may be false positives caused by sequencing, alignment errors, or genomic repeat sequences [25, 32]. An average of SNP-indices of SNPs located in a given genomic interval was calculated using the sliding window analysis with a $1 \mathrm{Mb}$ window size and $10 \mathrm{~kb}$ increment $[25,54]$. In this study, SNP-index $=1$ if all the short reads came from the parent MT1, and SNP-index $=0$ if all the short reads came from the parent SICAU1212. $\Delta$ (SNPindex) was then calculated by subtracting SNP-index of low bulk from SNP index of high bulk. The SNP-index graphs for high bulks and low bulk, and corresponding $\Delta$ (SNP-index) Manhattan graphs were plotted against the position of each sliding window in the reference genome (B73-RefGen_v4). The $\Delta$ (SNP-index) value of candidate genomic regions associated with a target trait should be significantly different from 0 ; therefore, candidate genomic regions for PEDS were identified using the hypothesis proposed by Takagi et al. [25].

\section{Validation of QTL-seq-derived genomic regions by traditional QTL mapping}

The candidate genomic regions for PEDS identified by QTL-seq were validated using traditional QTL analysis in three environments. Briefly, InDel markers were identified by aligning high bulks and low bulk, and the primers were designed based on the methods described in the previous study [55]. The InDel markers located on chromosomes $1,3,6$, and 8 were selected for polymorphism screening between the parents SICAU1212 and MT1. Then, the polymorphic markers were used in genotyping the $\mathrm{F}_{2}$ population with 36 plants derived from a cross between SICAU1212 and MT1 to calculate the allele ratios, excluding the markers with serious segregation distortion as determined by chi-square analysis. Subsequently, the markers that followed the expected Mendelian segregation ratio were utilized for genotyping the $\mathrm{BC}_{3} \mathrm{~F}_{2}$ populations in the $14 \mathrm{JH}$ and $18 \mathrm{WJ}$ environments, and the $\mathrm{BC}_{4} \mathrm{~F}_{2}$ population in the $15 \mathrm{WJ}$ environment. The genotyping data were used to construct the local genetic linkage map using MAPMAKER/EXP 3.0 [56], and the genetic map distances $(\mathrm{cM})$ were calculated following Kosambi mapping function [57]. Combining the genetic linkage information and phenotyping data, QTL analysis for PEDS was conducted with QTL IciMapping 4.1 (http://www.isbreeding.net/) using the inclusive composite interval mapping of additive (ICIM-ADD) and the two locus epistatic QTL (ICIM-EPI) modules [33].

\section{Abbreviations}

PEDS: Percentage of cupules lacking the pedicellate spikelet; ICIM: Inclusive composite interval mapping; QTL: Quantitative trait locus/loci; SEM: Scanning electron microscopy; IM: Inflorescence meristem; SPM: Spikelet pair 
meristems; SM: Spikelet meristems; PVE: Phenotypic variation explained; BSA Bulked sample analysis; NGS: Next-generation sequencing.

\section{Supplementary Information}

The online version contains supplementary material available at https://doi. org/10.1186/s12870-021-03353-3.

Additional file 1: Figure S1. Diagram of the construction of the advanced mapping population through phenotypic recurrent selection. Figure S2. SNP-index graphs of high PEDS bulks and low PEDS bulk, and $\triangle$ (SNP-index) graphs in three environments. Figure S3. Frequency distribution of $\mathrm{BC}_{3} \mathrm{~F}_{2}$ and $\mathrm{BC}_{4} \mathrm{~F}_{2}$ populations used for $\mathrm{QTL}$ mapping in three environments.

Additional file 2: Table S1. Sequencing of maize parent line and bulks, and mapping of sequence reads. Table $\mathbf{S 2}$. The information on markers used in traditional QTL mapping.

Additional file 3: Table S3. Genotypes and phenotypes of the mapping populations using traditional QTL mapping.

\section{Acknowledgements}

We would like to thank Shenzhen Huada Gene Technology Co., Ltd. (https:// www.genomics.cn/) for whole-genome resequencing. We also would like to thank EditSprings (https://www.editsprings.com/) for English language editing.

\section{Authors' contributions}

J. L. and T. R. conceived the experiment. D. T., K. H., Y. Y., and L. Z. constructed the mapping populations. Z. C., D.T., K. H., L. Z. J. N., P. L., and L. W. performed phenotyping and genotyping of all populations. Z. C. and J.L. analyzed the data. Z. C. and J. L wrote and revised the manuscript. All authors reviewed and approved this submission.

\section{Funding}

This research was supported by the National Basic Research Program of China (the "973" project, 2014CB138203), the State Key Laboratory of Grassland Agro-ecosytems (SKLGAE201509), the National Natural Science Foundation of China (31101161), and and the Double-Support Plan of Sichuan Agricultural University.

\section{Availability of data and materials}

The raw data and materials available on request from the authors.

\section{Declarations}

\section{Ethics approval and consent to participate}

We comfirm that the maize landrace Silunuo was collected from Yunnan Province, China by Maize Research Institute, Sichuan Agricultural University, maize inbred line SICAU1212 was bred from Silunuo by us, teosinte MT1 (accession number: 1 1394) was obtained from the International Maize and Whea Improvement Center (CIMMYT). The legality of these seeds complies with the IUCN Policy Statement on Research Involving Species at Risk of Extinction and the Convention on the Trade in Endangered Species of Wild Fauna and Flora. All field experiments were conducted in accordance with the local legislation of China.

\section{Consent for publication}

Not applicable.

\section{Competing interests}

The authors declare that they have no competing interests.

\section{Author details}

${ }^{1}$ Maize Research Institute, Sichuan Agricultural University, No.211 Huiming Road, Wenjiang District, Chengdu 611130, Sichuan, China. ${ }^{2}$ Industrial Crop Research Institute, Sichuan Academy of Agricultural Science, No.159 Huajin Avanue, Qingbaijiang District, Chengdu 610300, Sichuan, China.
Received: 27 August 2021 Accepted: 18 November 2021

Published online: 04 December 2021

\section{References}

1. Wang $H$, Nussbaum-Wagler $T$, Li B, Zhao Q, Vigouroux Y, Faller M, et al. The origin of the naked grains of maize. Nature. 2005;436(7051):714-9.

2. Doebley J. The genetics of maize evolution. Annu Rev Genet. 2004;38:37-59.

3. Kumar A, Singh N, Adhikari S, Joshi A. Morphological and molecular characterization of teosinte derived maize population. Indian J Genet. 2019;79(4):670-7

4. Upadyayula N, Da Silva H, Bohn MO, Rocheford T. Genetic and QTL analysis of maize tassel and ear inflorescence architecture. Theor Appl Genet. 2006;112(4):592-606

5. Doebley J, Stec A, Kent B. Suppressor of sessile spikelets1 (Sosl): a dominant mutant affecting inflorescence development in maize. Am J Bot. 1995:82(5):571-7.

6. Collins GN, Kempton JH. A teosinte-maize hybrid. J Agric Res. 1920;19:1-37

7. Doebley J, Stec A, Wendel J, Edwards M. Genetic and morphological analysis of a maize-teosinte F2 population: implications for the origin of maize. Proc Natl Acad Sci U S A. 1990;87(24):9888-92.

8. Langham DG. The inheritance of intergeneric differences in ZeaEuchlaena hybrids. Genetics. 1940;25(1):88

9. Szabó VM, Burr B. Simple inheritance of key traits distinguishing maize and teosinte. Mol Gen Genet. 1996;252(1):33-41.

10. Mangelsdorf PC. The origin and evolution of maize. In: Advances in genetics, Academic Press. 1947;1:161-207.

11. Rogers JS. The inheritance of inflorescence characters in maize-teosinte hybrids. Genetics. 1950:35(5):541.

12. Doebley J, Stec A. Genetic analysis of the morphological differences between maize and teosinte. Genetics. 1991;129(1):285-95.

13. Doebley J, Stec A. Inheritance of the morphological differences between maize and teosinte: comparison of results for two F2 populations. Genetics. 1993:134(2):559-70.

14. Lauter N, Doebley J. Genetic variation for phenotypically invariant traits detected in teosinte: implications for the evolution of novel forms. Genetics. 2002;160(1):333-42.

15. Doebley J, Stec A. Gustus C: teosinte branched1 and the origin of maize: evidence for epistasis and the evolution of dominance. Genetics. 1995:141(1):333-46.

16. Salvi S, Tuberosa R. To clone or not to clone plant QTLS: present and future challenges. Trends Plant Sci. 2005;10(6):297-304.

17. Guo G, Wang S, Liu J, Pan B, Diao W, Ge W, et al. Rapid identification of QTLs underlying resistance to cucumber mosaic virus in pepper (Capsicum frutescens). Theor Appl Genet. 2017;130(1):41-52.

18. Lebowitz R, Soller M, Beckmann J. Trait-based analyses for the detection of linkage between marker loci and quantitative trait loci in crosses between inbred lines. Theor Appl Genet. 1987;73(4):556-62.

19. Michelmore RW, Paran I, Kesseli R. Identification of markers linked to disease-resistance genes by bulked segregant analysis: a rapid method to detect markers in specific genomic regions by using segregating populations. Proc Natl Acad Sci U S A. 1991;88(21):9828-32.

20. Zou C, Wang P, Xu Y. Bulked sample analysis in genetics, genomics and crop improvement. Plant Biotechnol J. 2016;14(10):1941-55.

21. Schneeberger K, Ossowski S, Lanz C, Juul T, Petersen AH, Nielsen KL, et al. SHOREmap: simultaneous mapping and mutation identification by deep sequencing. Nat Methods. 2009:6(8):550.

22. Ehrenreich IM, Torabi N, Jia Y, Kent J, Martis S, Shapiro JA, et al. Dissection of genetically complex traits with extremely large pools of yeast segregants. Nature. 2010;464(7291):1039.

23. Austin RS, Vidaurre D, Stamatiou G, Breit R, Provart NJ, Bonetta $\mathrm{D}$, et al. Next-generation mapping of Arabidopsis genes. Plant J. 2011;67(4):715-25.

24. Abe A, Kosugi S, Yoshida K, Natsume S, Takagi H, Kanzaki H, et al. Genome sequencing reveals agronomically important loci in rice using MutMap. Nat Biotechnol. 2012:30(2):174.

25. Takagi H, Abe A, Yoshida K, Kosugi S, Natsume S, Mitsuoka C, et al QTL-seq: rapid mapping of quantitative trait loci in rice by whole 
genome resequencing of DNA from two bulked populations. Plant J. 2013;74(1):174-83.

26. Sun X, Liu D, Zhang X, Li W, Liu H, Hong W, et al. SLAF-seq: an efficient method of large-scale de novo SNP discovery and genotyping using high-throughput sequencing. PLoS One. 2013;8(3):e58700.

27. Zhang H, Wang X, Pan Q, Li P, Liu Y, Lu X, et al. QTG-Seq accelerates QTL fine mapping through QTL partitioning and whole-genome sequencing of bulked segregant samples. Mol Plant. 2019;12(3):426-37.

28. Chen Q, Song J, Du W-P, Xu L-Y, Jiang Y, Zhang J, et al. Identification and genetic mapping for rht-DM, a dominant dwarfing gene in mutant semidwarf maize using QTL-seq approach. Gene Genom. 2018;40(10):1091-9.

29. Olsen M, Yao N, Tadesse B, Das B, Gowda M, Semagn K, et al. Mapping genomic regions associated with Maize Lethal Necrosis (MLN) using QTLseq. Poster. Nairobi, Kenya: ILRI. 2016. https://cgspace.cgiar.org/handle/ 10568/70239? show=full.

30. Chen Q, Song J, Du W-P, Xu L-Y, Jiang Y, Zhang J, et al. Identification, mapping, and molecular marker development for Rgsr8. 1: a new quantitative trait locus conferring resistance to Gibberella stalk rot in maize (Zea mays L.). Front Plant Sci. 2017:8:1355.

31. Zheng M, Yang T, Liu X, Lü G, Zhang P, Jiang B, et al. qRf8-1, a novel QTL for the fertility restoration of maize CMS-C identified by QTL-seq. Genes Genom Genet. 2020;10(7):2457-64.

32. Lu H, Lin T, Klein J, Wang S, Qi J, Zhou Q, et al. QTL-seq identifies an early flowering QTL located near flowering locus T in cucumber. Theor Appl Genet. 2014;127(7):1491-9.

33. Li C, Bai G, Carver BF, Chao S, Wang Z. Single nucleotide polymorphism markers linked to QTL for wheat yield traits. Euphytica. 2015;206(1):89-101.

34. Benz BF, Iltis HH. Studies in archaeological maize I: the "wild" maize from San Marcos cave reexamined. Am Antiq. 1990;55(3):500-11.

35. Benz BF. Archaeological evidence of teosinte domestication from Guilá Naquitz, Oaxaca. Proc Natl Acad Sci USA. 2001;98(4):2104-6.

36. Doebley J, Stec A, Hubbard L. The evolution of apical dominance in maize. Nature. 1997;386(6624):485-8.

37. Carlborg Ö, Haley CS. Epistasis: too often neglected in complex trait studies? Nat Rev Genet. 2004;5(8):618-25.

38. Yamanaka N, Watanabe S, Toda K, Hayashi M, Fuchigami H, Takahashi R, et al. Fine mapping of the FT1 locus for soybean flowering time using a residual heterozygous line derived from a recombinant inbred line. Theor Appl Genet. 2005;110(4):634-9.

39. Watanabe S, Xia Z, Hideshima R, Tsubokura Y, Sato S, Yamanaka N, et al. A map-based cloning strategy employing a residual heterozygous line reveals that the GIGANTEA gene is involved in soybean maturity and flowering Genetics. 2011:188(2):395-407.

40. Hung H-Y, Shannon LM, Tian F, Bradbury PJ, Chen C, Flint-Garcia SA, et al. ZmCCT and the genetic basis of day-length adaptation underlying the postdomestication spread of maize. Proc Natl Acad Sci U S A. 2012;109(28):E1913-21.

41. Huang $C$, Sun $H$, Xu D, Chen Q, Liang Y, Wang X, et al. ZmCCT9 enhances maize adaptation to higher latitudes. Proc Natl Acad Sci U S A. 2018;115(2):E334-41.

42. Bechoux N, Bernier G, Lejeune P. Environmental effects on the early stages of tassel morphogenesis in maize (Zea mays L.). Plant Cell Environ. 2000;23(1):91-8.

43. Boden SA, Cavanagh C, Cullis BR, Ramm K, Greenwood J, Finnegan EJ, et al. Ppd-1 is a key regulator of inflorescence architecture and paired spikelet development in wheat. Nat Plants. 2015;1(2):14016.

44. Meng X, Muszynski MG, Danilevskaya ON. The FT-like ZCN8 gene functions as a floral activator and is involved in photoperiod sensitivity in maize. Plant Cell. 2011;23(3):942-60.

45. Zeng M, Yang T, Wang P. The relative analyses on maize cultivar Menghai four-row wax. J Genet Genomics. 1981;8(1):91-6. (In chinese).

46. Tian M, Tan G, Liu Y, Rong T, Huang Y. Origin and evolution of Chinese waxy maize: evidence from the Globulin-1 gene. Genet Resour Crop Ev. 2009;56(2):247-55.

47. Saghai-Maroof MA, Soliman KM, Jorgensen RA, Allard R. Ribosomal DNA spacer-length polymorphisms in barley: Mendelian inheritance, chromosomal location, and population dynamics. Proc Natl Acad Sci U S A. 1984;81(24):8014-8.

48. Pandey MK, Khan AW, Singh VK, Vishwakarma MK, Shasidhar Y, Kumar $V$, et al. QTL-seq approach identified genomic regions and diagnostic markers for rust and late leaf spot resistance in groundnut (A rachis hypogaea L.). Plant Biotechnol J. 2017;15(8):927-41.

49. Singh VK, Khan AW, Jaganathan D, Thudi M, Roorkiwal M, Takagi H, et al. QTL-seq for rapid identification of candidate genes for 100-seed weight and root/total plant dry weight ratio under rainfed conditions in chickpea. Plant Biotechnol J. 2016;14(11):2110-9.

50. Deokar A, Sagi M, Daba K, Tar'an B. QTL sequencing strategy to map genomic regions associated with resistance to ascochyta blight in chickpea. Plant Biotechnol J. 2019;17(1):275-88.

51. Katta MA, Khan AW, Doddamani D, Thudi M, Varshney RK. NGS-QCbox and raspberry for parallel, automated and rapid quality control analysis of large-scale next generation sequencing (Illumina) data. PLoS One. 2015;10(10):e0139868.

52. Li H, Durbin R. Fast and accurate short read alignment with burrowswheeler transform. Bioinformatics. 2009;25(14):1754-60.

53. Kosugi S, Natsume S, Yoshida K, MacLean D, Cano L, Kamoun S, et al. Coval: improving alignment quality and variant calling accuracy for nextgeneration sequencing data. PLoS One. 2013;8(10):e75402.

54. Zhang X, Wang W, Guo N, Zhang Y, Bu Y, Zhao J, et al. Combining QTL-seq and linkage mapping to fine map a wild soybean allele characteristic of greater plant height. BMC Genomics. 2018;19(1):226.

55. Liu J, Qu J, Yang C, Tang D, Li J, Lan H, et al. Development of genomewide insertion and deletion markers for maize, based on next-generation sequencing data. BMC Genomics. 2015;16(1):601.

56. Lander ES, Green P, Abrahamson J, Barlow A, Daly MJ, Lincoln SE, et al. MAPMAKER: an interactive computer package for constructing primary genetic linkage maps of experimental and natural populations. Genomics. 1987;1(2):174-81.

57. Kosambi DD. The estimation of map distances from recombination values. Ann Eugenics. 1994;12:172-5.

\section{Publisher's Note}

Springer Nature remains neutral with regard to jurisdictional claims in published maps and institutional affiliations.

Ready to submit your research? Choose BMC and benefit from

- fast, convenient online submission

- thorough peer review by experienced researchers in your field

- rapid publication on acceptance

- support for research data, including large and complex data types

- gold Open Access which fosters wider collaboration and increased citations

- maximum visibility for your research: over $100 \mathrm{M}$ website views per year

At BMC, research is always in progress.

Learn more biomedcentral.com/submissions 